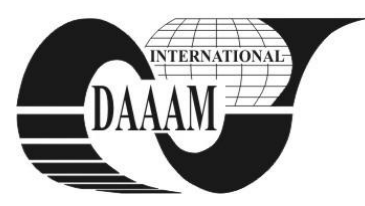

\title{
A MAN AND HIS PLACE IN AUTOMATED AND ROBOTIC SYSTEMS
}

\author{
KYZEK, J[an]; HATIAR, K[arol]; ONDRIGA, M[artin] \& BOZEK, P[avol]
}

\begin{abstract}
This paper deals with human tasks in the operation of automated and robotic equipment and systems. Also deals with related ergonomic requirements, which in this case should be taken into account in their design. There are also considerations applicable mainly in the states after the transformation industry.
\end{abstract}

Key words: ergonomics, automation, robotization, man vs automat, ergonomics program

\section{INTRODUCTION}

We are currently witnessing intensification of requirements for a solution and implementation of robotic and automated equipment and systems in corporate practice. Extension of the use of advanced robots and automated systems are forced to think seriously about the possible consequences of this process in a wide range of social and labour aspects, such as the level and structure of employment, the need for skilled labour, Labour, prolonging the working day, etc. shifts (Hatiar, 1988).

In relation to the development of the state of supply and demand in the global market appear requirements for production and assembly systems that can flexibly adapt to changes in supply and demand. In addition to fully automatic systems are still using systems that can combine the advantages of flexible automatic equipment with low variable costs of assembly reliability investment associated with manual assembly workstations.

When dealing with automated and robotized workplaces appear significant technical problems. The main problem in implementing such systems is the economy, especially the question of financial cost and effectiveness.

If the automation and robotics has been successfully applied have to be effective for small production batches of a wide range of products. The solution there could be in modularity of automated and robotic systems.

Reducing of efficiency of automation e.g. in assembly is influenced by:

- Product design does not allow the use of modern technologies;

- Specific traits of assembly process;

- Low flexibility (lack of adaptability) technology changing requirements resulting from changes in supply and demand in the global market.

The situation may improve standardization and also deepening the implementation of flexible assembly systems and industrial robots.

The rapid development of new products is that the assembly is often at least at the beginning of production carried out at a lower level of technology. The reason is lack of time and lack of available technical options for the deployment of highlymechanized or automated assembly using robots. Lower levels of assembly with handiwork and partially mechanized workplaces will therefore retain importance also in the future. It is generally assumed that in the foreseeable future the human work will not be excluded from the assembly process.

It is expected the transfer of human activity from monotonous assembly work on synchronous lines to the management, monitoring and operation of high performance automated equipment. At the forefront is getting mounted in small doses, which can be more effective combination of small flexible workplaces with high-quality technical equipment and a more pronounced adaptation options for human development and the flexibility of automatic and robotic systems through their modularity.

It is assumed that one should also in robotic and automated equipment and systems in four basic areas involved in the work of automatic and robotic assembly systems:

- Direct involvement in the work system (e.g., parallel work on hand for either atypical working operations, or workplaces back to work in case of power equipment);

- Supply system (providing the conditions for its operation);

- Providing feedback resulting from the verification of the quality of production;

- Operating system.

A flexible manufacturing and assembly system, depending on the degree of automation reduces the physical demands of the man, but may negatively impact on his psyche. For example, the control centres in the working process can be long periods of inactivity (when the process is managed without faults) irregularly alternated with short periods of heavy loads and congestion in situations where it is now necessary to solve problems.

Implementation of the automatic and robotic devices and systems that excludes persons from direct access to certain work activities, contributes to improving working conditions, particularly in terms of safety. However, there are appearing gradually new risks, which require the development of new standards and measures in area of Occupational Health Safety

\section{ERGONOMIC DESIGN OF AUTOMATED AND ROBOTIC EQUIPMENT AND SYSTEMS}

As we saw in the introduction, it is assumed that the automated and robotic systems in the near future will need human assistance. This is the reason why even at this level of technology will be necessary respect man and create favourable conditions for its effective work performance.

Automatic and robotic systems are typical by faster production. Therefore, any delay is a significant financial loss. There is therefore necessary to ensure good conditions for monitoring system as well as prompt removal of repairs and maintenance.

Control centres must be solved to provide an operator who is responsible for monitoring of the system working comfort necessary in order to maintain attention for a follow-up work process so that also quickly and effectively during this process to intervene, through appropriate drivers. Moreover, such a system needs to be addressed, so that the operator was able to identify as quickly as possible failures and deficiencies of a system that could be as soon as possible to ensure their removal.

The grounds for such a solution in terms of ergonomics, provides decree of Ministry of Health of the Slovak Republic No. 542/2007 (***, 2007). In accordance with this document we proposed within our project for specific needs of Slovakia dimensions for a location of aggregates enabling easy 
manipulation during their repairs or replacements. We have defined the following dimensions and location of areas where you can conveniently and efficiently manipulate objects and to perform the sitting and standing activities, which are suitable for location of all types of tales (from scales and dials to control an interactive computer display) directly equipment or operator of a monitoring desk .. The data may not be published in this paper for their size. They will, however, first presented at a conference organized by the Technical University in Zvolen on 13.10.2011 and will also be published in proceedings of that event (Hatiar \& Bozek, 2011).

A prompt removal of such defects significantly contribute system design that allows you quickly identify the cause of the malfunction, to locate the place of failure and the easiest access to the site so that it can be removed as quickly as possible. For this purpose we are under the Ministry of Health Decree no. 542 / 2007 (***, 2007) requirements derived the dimensions and zones for comfortable reaches necessary in taking up maintenance and repair defects but also for maximum comfortable speed of labour movements in repair and maintenance of automatic and robotic devices and systems.

There are also insignificant questions of industrial design of automated and robotic devices and systems. The basic mission of industrial design solution is here to optimize interaction of factors related to the function, shape, aesthetic requirements, but also technical and utilitarian characteristics.

Shape and colour solution should respect the functional requirements (such as easy removing of covers the speed and ease of maintenance and repairs) but also the requirements of a positive impact on the psyche of operators, maintenance and repairers. The research and solutions in this area is currently focused in Slovak Republic especially Mechanical Engineering Faculty in Košice.

\section{ERGONOMIC ASPECTS OF THE OPERATION OF AUTOMATED AND ROBOTIC SYSTEMS}

It turns out that in the near future in the operation of automated and robotic equipment and systems (which are increasingly being installed in the well) will have one to carry out activities such as (Hatiar, 1988):

- Programming;

- Operation and maintenance;

- Residual tasks.

These residual tasks can be divided into 4 categories:

- Manual handling when picking, handling, procurement and transportation of materials, manufacturing finished products;

- Monitoring

- Manual intervention when the lack of office machines and robots

- Manually carrying out assembly operations in additional workplaces (e.g. for assembly of non-standard parts that cannot be the current level of technology to automate, or for emergency situations, in the case of larger failures of automatic, robotic devices and systems).

Downtime, automated equipment and systems cause significantly higher production losses than conventional assembly workplaces. It is therefore necessary to ensure conditions for shortening of time needed to identify the causes of failures, time to perform the repairs, adjustment and maintenance of equipment and systems. On the ergonomic measures implemented under construction is necessary in practice to establish appropriate service organization of work, prompt repair and maintenance to ensure effectiveness of operation of the automated equipment and systems. Although there is a beneficial form of systematic approach, suitable ergonomics program (Hatiar, et al. 2009).

\section{CONCLUSION}

Our knowledge of available sources indicates that automatic and robotic equipment cannot exclude a man from work in the near future. Therefore, it remains important to pay attention to ergonomic requirements.

The design of such techniques will need to comply with ergonomic requirements of the position and size distribution of aggregates in terms of equipment availability at the exchange and repair. For this purpose, we derived the data (Hatiar. Bozek 2011) in addition to documents from the Ministry of Health Decree number 542/2007 (***, 2007). Implementation of them will help to facilitate activities of the operator and also bring increasing to efficiency of maintenance and repair.

Operation of automated and robotic systems will be managed so that human operators will not reduce the effectiveness of high-performance automatic techniques. This should be implemented through adequate ergonomic programs (Hatiar, et al. 2009)

Research of the impact of working conditions in operation of automated and robotic systems to employees in enterprises we recommend perform by retrospective cohort studies in analysis before implementation of ergonomic program and bycohort studies evaluating the effectiveness of the implemented ergonomic measures.

We suppose that such an understanding man's relationship with high-performance automated and robotic technology will contribute to improving the production efficiency and also to sustainable development.

\section{ACKNOWLEDGEMENT}

This work was supported by KEGA - 3-7285_09 Content, Integration and Design University Textbook "Specialized Robotics Systems in Print and Interactive Modules".

\section{REFERENCES}

Cibulka, V. (2010) Complex Approach to Goods Quality Improvement for the Company and the Customer. - 1st ed. Köthen : Hochschule Anhalt, 2010, 103pg. ISBN 978-386011-035-5

Hatiar, K. (1988) Ergonomics and design solutions for automated assembly equipment and systems. In.: Proceedings of the National Seminar "People in robotic systems", the theme of "Engineering-psychological aspects of design automation systems" Melichercikova, J. (ed), House of technichnilogy ČSVTS, Bratislava, j 1988 pp. 12 $-15$

Hatiar, K., Cook, T.M.. Sakal, P., Bozek, P., Mihok, J., (2009) Application of a HCS model $3 \mathrm{E}$ in the virtual control of a robotic workplace. In: Annals of DAAAM and Proceedings of DAAAM Symposium. - ISSN 1726-9679. - Vol. 20, No. 1 Annals of DAAAM for 2009 \& Proceedings of the 20th international DAAAM symposium "Intelligent manufacturing \& automation: Focus on theory, practice and education" 25 - 28th November 2009, Vienna, Austria. - Vienna : DAAAM International Vienna, 2009. pp. 04050406 - ISBN 978-3-901509-70-4

Hatiar, K., Božek, P., (2011) Ergonomics aspects of automation and robotics in technological process. In: Proceedings of , $7^{\text {th }}$ scientific conference with international participatioin "Informatics and Automation in Process Control" 2011, Technology University Zvolen, Deparment of Informatics and AutomationTtechnology, Slovak Reublic, Zvolen, TU Zvolen, 2011, pp 15 - 21, ISBN 978-80-228-2267-1

Zimmermann CL, Hatiar KM, Cook TM. (1998) A comparison of work-related musculoskeletal disorders among operating engineers in the United States and Slovakia. Central European J Occup Environ Med 4 (3) 1998, pp 232-246

*** (2007) Decree of Ministry of Health of the Slovak Republic. 542/2007 registered in the collection of laws in august, 16th 2007 for details on health protection against physical stress at work, mental workload and sensory stress at work, (In Slovak) pp. 3876 - 3901 Ministry of Health of the Slovak Republic, Bratislava, 2007 